\title{
Gender-Dependent Association of the Functional Catechol-O-Methyltransferase Val I58Met Genotype with Sensation Seeking Personality Trait
}

\author{
Undine E Lang*, ${ }^{*, 5}$, Malck Bajbouj ${ }^{2,5}$, Thomas Sander ${ }^{3}$ and Juergen Gallinat ${ }^{4}$ \\ 'Department of Psychiatry and Psychotherapy, University Hospital Carl Gustav Carus, Dresden, Germany; ${ }^{2}$ Department of Psychiatry and \\ Psychotherapy, Charité University Medicine Berlin, Campus Benjamin Franklin, Berlin, Germany; ${ }^{3}$ Department of Genetics, Gene Mapping Center, \\ Max-Delbrück-Center for Molecular Medicine, Berlin, Germany; ${ }^{4}$ Department of Psychiatry and Psychotherapy, Charité University Medicine \\ Berlin, Campus Mitte, Berlin, Germany
}

\begin{abstract}
The gene encoding cathechol-O-methyltransferase (COMT) contains a common functional missense polymorphism (Vall58Met) that regulates dopamine in an allele-dependent manner. A pivotal role of dopamine neurotransmission in the prefrontal cortex has been implicated in drug-seeking behavior and related personality traits, such as sensation seeking, with some evidence for a gender-specific association. Here, we tested the hypothesis that the COMT Vall 58Met polymorphism modulates the personality dimension, sensation seeking, in a gender-dependent manner. Study sample included 214 male (age $38.1 \pm 12.6$ years) and 218 female (age $36.1 \pm$ I 3.6 years) healthy volunteers, who were assessed with Zuckerman's sensation-seeking scale and genotyped for the Vall58Met polymorphism (dbSNP:rs4680). Univariate analysis of variance showed that the sensation seeking score was significantly affected by a COMT genotype $\times$ gender interaction $(F=5.330, d f=2, p=0.005)$. The Vall 58Met polymorphism was associated with the sensation seeking personality trait in women only. The highest scores in the sensation-seeking scale and in three of the four subscales were observed in female subjects with the $\mathrm{Val} / \mathrm{Val}$ genotype relative to women carrying the Met allele. Our results suggest that high COMT enzyme activity associated with the $\mathrm{Val}$ allele predisposes to high sensation seeking scores in female subjects and add to increasing evidence for a gender specific role of COMT in normal and dysfunctional behavior.
\end{abstract}

Neuropsychopharmacology (2007) 32, 1950-1955; doi:I0. I038/sj.npp. I 301335; published online I 4 February 2007

Keywords: catechol-O-methyltransferase; COMT; Vall58Met; dopamine; personality; sensation seeking

\section{INTRODUCTION}

Twin studies have suggested heritability estimates for personality traits with up to 60\% (Lin et al, 2006; Heiman et al, 2004). Current models of personality include the dimensions extraversion, exploration, and novelty seeking at a fundamental level. These features are central to the definition of the particular personality trait referred to as sensation seeking (Zuckerman, 1990), which reflects a tendency toward exploratory excitability in response to novelty, impulsiveness in decision-making, risk taking behavior, and disorderliness with quick loss of temper.

It has been shown in animal experiments that novelty processing is mediated by dopaminergic neurotransmission involving the hippocampus, ventral tegmental area, and

*Correspondence: Dr UE Lang, Department of Psychiatry and Psychotherapy, University Hospital of Dresden, Fetscherstr 74, 01307 Dresden, Germany, Tel: +49 35। 458 3683/+49 I63 7568822, Fax: + 49 35। 458 4324, E-mail: undine.lang@gmx.de

${ }^{5}$ These authors contributed equally to this work.

Received 29 September 2006; revised 5 December 2006; accepted 18 December 2006 nucleus accumbens (Legault and Wise, 2001; Ljungberg et al, 1992). Both, reward seeking and exploratory behavior is characteristic for novelty and sensation seeking behavior and has been assessed in questionnaires like the Tridimensional Personality Questionnaire (TPQ) or the sensationseeking scale (Cloninger, 1987; Zuckerman, 1990). Research on novelty seeking and sensation seeking in the past two decades has focused on central dopaminergic activity (Cloninger, 1987; Ebstein et al, 1996; Shiraishi et al, 2006). Accordingly, genetic studies have reported associations of the novelty seeking personality trait with polymorphisms in the dopamine receptor and transporter genes (Noble et al, 1998; Sullivan et al, 1997; Benjamin et al, 1996; Ebstein et al, 1996). In recent years, the COMT has been investigated extensively due to its crucial role of this enzyme in the metabolism of catecholamines by inactivating them in the synaptic cleft. A common functional single nucleotide polymorphism (SNP) of the COMT gene (dbSNP rs4680. c.675G $>$ A, p.Val158Met) decreases COMT activity by coding for the amino acid methionine instead of valine (Lachman et al, 1996). In the dorsolateral prefrontal cortex and lymphocytes COMT activity has been shown to be $40 \%$ 
higher in human subjects with the Val allele than in those with the Met allele (Chen et al, 2004). The Val allele has been proposed to lead to lower synaptic dopamine levels in the prefrontal cortex and was associated with ineffective prefrontal activation in brain imaging studies (Winterer et al, 2006b; Chen et al, 2004; Akil et al, 2003; Gallinat et al, 2003a). This indicates that COMT genotype is a heritable aspect of prefrontal dopamine regulation which suggests this genetic variation to modulate inhibitory aspects of emotion and behavior (Lisman and Grace, 2005).

Findings of studies investigating associations between COMT gene and personality were heterogeneous, especially with respect to the phenotypes investigated and the personality scales applied. Of note, several authors found genetic variants of the COMT Val158Met gene play a role in personality dimensions in female subjects but not in male subjects (Kim et al, 2006; Stein et al, 2005; Qian et al, 2003; Eley et al, 2003). For instance, in a sample of community subjects selected for either high or low neuroticism, evidence for an association with COMT Val158Met genotype with high neuroticism was found in female subjects but not in male subjects (Eley et al, 2003). A sexually dimorphic effect of COMT Val158Met alleles has also recently been observed in attention deficit hyperactivity disorder (ADHD), a diagnosis which is phenomenologically related to novelty and sensation seeking personality traits (Qian et al, 2003). The genetic underpinnings of novelty seeking have also been investigated in healthy subjects. High novelty seeking scores have been reported in subjects with $\mathrm{Val} / \mathrm{Val}$ genotype compared to the Val/Met or Met/Met individuals by Reuter and Hennig (2005), a result which was also observed in a female sample investigated by Tsai et al (2004). However, sexually dimorphic effects of the COMT genotype on novelty or sensation seeking have not been investigated in detail.

In our study, we aimed to investigate gender specific effects of the COMT Val158Met polymorphism on the sensation seeking personality trait in a large sample of 432 carefully selected healthy subjects balanced for gender distribution. The use of illegal drugs was explicitly excluded in our sample, as it has been shown that novelty seeking scores are closely related to substance abuse (Chakroun et al, 2004). As novelty seeking has been looked upon as a very heterogeneous trait and results in a heterogeneous phenotype definition, we used as alternative to Cloninger's Scale the sensation-seeking scale for the first time in this context. The sensation-seeking scale was firstly introduced by Zuckerman (1990), which shows overall relationships to both high novelty seeking and low harm avoidance (McCourt et al, 1993). It was hypothesized that the Val allele is associated with the sensation-seeking dimension in female subjects but not in male subjects.

\section{METHODS}

\section{Subjects}

The study was approved by the ethics committee of the Charité University Medicine, Campus Mitte (Berlin, Germany). In total, 432 volunteers of German descent (214 male, age $38.1 \pm 12.6$ years; 218 female, age $36.1 \pm 13.6$ years) recruited through newspaper advertisements were exam- ined. All subjects gave written informed consent. Somatic as well as psychiatric health status was evaluated by a structured psychiatric interview (Mini-International Neuropsychiatric Interview) (Sheehan et al, 1998) performed by a psychiatrist. Subjects were excluded when fulfilling the criteria for an axis I or axis II disorder according to DSM-IV criteria. Further reasons for exclusion were neurological and general medical disorders or any clinically relevant abnormalities. For additional methodological details see (Gallinat et al, 2003a). Genotype investigations have been performed in subsamples of the present sample $(n=432)$ with regard to genetic variants in the serotonin system (Gallinat et al, 2003b, 2005) ( $n=185)$, (Lang et al, 2004) $(n=228)$ and the dopamine system (Gallinat et al, 2003a) $(n=170)$.

\section{Assessment of Personalty Traits}

Sensation seeking has been defined as a human trait characterized by the need for 'varied, novel, and complex sensations and experience and the willingness to take physical and social risks for the sake of such experience' (Zuckerman, 1979). Previously performed factor analysis of the response of subjects in different countries have shown four dimensions (factors) of the sensation seeking consisting of 10 items each and a sum score (Zuckerman, 1979). The factor thrill and adventure seeking contains items that express a desire to engage in certain kinds of physical activities, like parachuting or scuba diving, that are risky but promise certain kinds of physical sensations. Experience seeking suggests the desire to seek new experience through the senses and the mind, using either external stimuli (music, art, travel), alteration of the mind through drugs, or engaging in a nonconformist style of life. Disinhibition comprises items describing a social-hedonistic orientation, with the pursuit of sensation through parties, drinking, and sex. The factor boredom susceptibility reflects a dislike of routine activities, boring people, and also suggests a restless reaction to a lack of stimulus variety. The sensation-seeking scale has shown both good internal and retest reliability, particularly for the total score on form $\mathrm{V}$ of the scale $(r=0.94$ over 3 weeks) (Zuckerman, 1979). The validity of the scale has been investigated extensively over three decades (Zuckerman and Kuhlman, 2000; Zuckerman, 1990; Gallinat, 1996).

\section{SNP Genotyping}

Genotyping of the SNP rs4680 (COMT c.675G > A, p.Val158Met) was carried out at the Gene Mapping Center (GMC) of the Max-Delbrück-Center in Berlin. Genotypes of rs 4680 were determined by a Taqman $5^{\prime}$-exonuclease assay, as described previously (Gallinat et al, 2003a). The call rate in more than 2500 individuals, including the present samples, was $>99 \%$. The genotyping reliability of the TaqMan assay was examined by genotyping of 186 duplicated DNA samples, which are not part of the present study. All duplicated samples displayed the same genotype as its reference sample. Mendelian inheritance was demonstrated in 80 nuclear families. Potential DNA admixture of study samples was excluded by genotyping of 20 highly polymorphic microsatellite markers. 


\section{Statistical Analyses}

Statistical calculations were carried out as indicated in the results section using SPSS for Windows (Release 12.0) ${ }^{\circledR}$. MANCOVA and post hoc ANCOVA were employed to investigate effects of genotype (factor), gender (factor), and age (covariate) on the personality trait sensation seeking (dependent variable). Correlation analysis was performed with Pearson correlation. All tests were performed at a level of significance equal to 0.05 .

\section{RESULTS}

The genotype frequency Met/Met $(n=118)$, Val/Met $(n=237), \mathrm{Val} / \mathrm{Val}(n=77)$ was $27.3,54.9$, and $17.8 \%$. The frequency of the alleles was: $\mathrm{Val}=0.453$ and $\mathrm{Met}=0.547$. The observed genotype counts in the present sample did not differ significantly from those expected according to the Hardy-Weinberg equilibrium.

No differences between genotypes were observed with regard to age or gender (see Table 1). The Sensation Seeking Sum score showed a significant correlation with age $(r=-0.363, p<0.001)$ indicating decreasing scores with increasing age and a significant gender difference with higher values in male subjects compared to female subjects $(t=4.781, p<0.001 ; t$-test; Figure 1$)$.

The ANCOVA showed that the dependent variable Sensation Seeking Sum score was significantly affected by factor 'gender' $(\mathrm{F}=18.001, \mathrm{df}=1, p<0.001)$, covariate 'age' $(\mathrm{F}=77.888, \mathrm{df}=1, p<0.001)$ and factor 'gender' $\times$ 'genotype' interaction (male, female; Met/Met, Val/Met, $\mathrm{Val} / \mathrm{Val} ; \mathrm{F}=5.330, \mathrm{df}=2, p=0.005)$ but not by the factor 'genotype' alone $(\mathrm{F}=0.815, \mathrm{df}=2, p=0.443)$. Owing to the 'gender' $x$ 'genotype' interaction further analyses were performed separately for male subjects and female subjects. The gender-related subsamples were similar in their sample sizes (218 female, 214 male) and did not differ in their genotypic distribution $\left(\chi^{2}=2.02, \mathrm{df}=2, p=0.364\right)$. Therefore, the power attributable to each gender-related subsample was similar.

In female subjects, MANCOVA revealed that the dependent variables Sensation Seeking Sum score and the four subscales were significantly affected by the factor 'genotype' $(\mathrm{F}=2.120, \mathrm{df}=8, p=0.033)$ and covariate 'age' $(\mathrm{F}=13.402$, $\mathrm{df}=4, p<0.001)$. The post hoc ANCOVA showed a significant association of the factor 'genotype' with the Sensation Seeking Sum score $(\mathrm{F}=5.191, \mathrm{df}=2, p=0.006)$, Boredom Susceptibility Score $(\mathrm{F}=5.510, \mathrm{df}=2, p=0.005)$, and Thrill and Adventure Seeking Score $(\mathrm{F}=3.032, \mathrm{df}=2$, $p=0.050$ ) but not Disinhibition or Experience Seeking Scores. In this model, $4.6 \%$ of the variance of the Sensation Seeking Sum score was explained by the COMT genotype

In the contrast analysis, female subjects scored significantly higher in the $\mathrm{Val} / \mathrm{Val}$ group than in the $\mathrm{Val} / \mathrm{Met}$ Group for Sensation Seeking Sum score $(p=0.002$; Figure 1$)$, Thrill and Adventure $(p=0.045)$, Disinhibition $(p=0.043)$, and Boredom susceptibility scores $(p=0.001)$. Additionally, $\mathrm{Val} / \mathrm{Val}$ female subjects also had significant higher scores than Met/Met female subjects in Thrill and Adventure Seeking $(p=0.018)$ and Sensation Seeking Sum score $(p=0.008)$.
Table I Clinical Data for Subjects Separated by COMT Vall58Met Genotype

\begin{tabular}{|c|c|c|c|c|}
\hline & Met/Met & Val/Met & Val/Val & Test result \\
\hline$N(\%)$ & I I8 (27.3) & $237(54.9)$ & 77 (17.85) & \\
\hline Gender (m/f) & $65 / 53$ & $113 / 124$ & $36 / 41$ & $N S^{a}$ \\
\hline Age $\pm S D(y)$ males & $38.9(13.7)$ & $38.2(12.8)$ & $36.0(11.8)$ & $N S^{b}$ \\
\hline Age $\pm S D(y)$ females & $35.9(13.4)$ & $36.6(13.6)$ & $34.6(14.0)$ & $N S^{b}$ \\
\hline
\end{tabular}

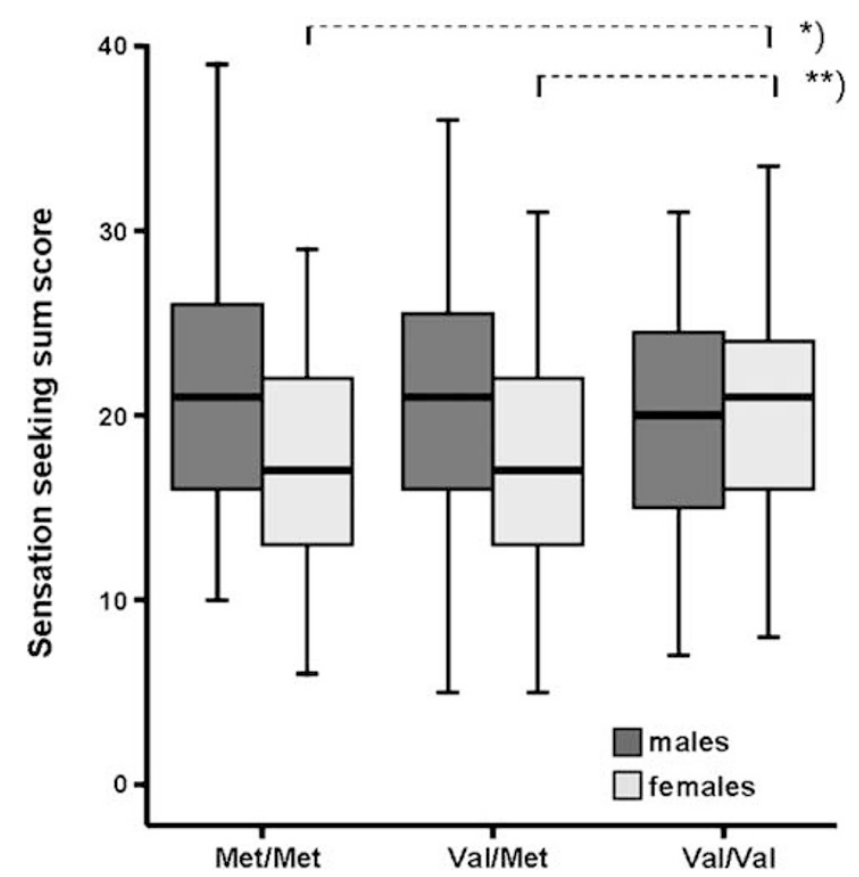

Figure I Sensation seeking sum scores are presented separately for gender and COMT Vall58Met genotype. Contrast analysis revealed significantly higher mean scores in Val/Val compared to Val/Met and Met/ Met female individual (see Results section). No genotype effect was found in male subjects. Note that within the group of female subjects $\mathrm{Val} / \mathrm{Val}$ individuals score equal to male participants. $* p<0.05$; $* * p<0.01$.

In male subjects, MANCOVA revealed no significant effect of the factor 'genotype' on the dependent variables Sensation Seeking Score and the four subscales but a significantly effect of the covariate 'age' $(\mathrm{F}=10.654, \mathrm{df}=4, p<0.001)$. The post hoc ANCOVAs did not show significant effects of factor 'genotype' on any of the subscale scores (Figure 1).

\section{DISCUSSION}

The major finding of this study is, that the COMT Val158Met polymorphism may be associated with the sensation seeking personality trait in women, with highest sensation seeking scores demonstrated for subjects bearing the $\mathrm{Val} / \mathrm{Val}$ genotype in comparison to the $\mathrm{Val} / \mathrm{Met}$ and Met/Met counterparts. This result was observed for the sum score and for three of the four subscales Thrill and Adventure Seeking, Disinhibition, and Boredom 
Susceptibility. Although power to detect a genetic influence on sensation seeking was similar in female subjects and male subjects, no association between the COMT Val158Met polymorphism and any sensation seeking score was observed for the male participants. The study confirms the previous observation that women as a whole group have lower sensation seeking scores relative to men with the exception that $\mathrm{Val} / \mathrm{Val}$ female subjects score equally to male subjects.

This finding is in line with recently published data showing highest scores of novelty seeking in volunteers with $\mathrm{Val} / \mathrm{Val}$ genotype compared to the Met carriers (Reuter and Hennig, 2005; Tsai et al, 2004). In the study of Tsai et al (2004) associations between the COMT genotype and TPQ personality traits were observed in a sample population of 120 healthy young Chinese females while men were not investigated. The data are in accordance with the biological concept of personality originally formulated by Cloninger (1987), who attributed the novelty seeking dimension to biological variations in the dopamine system. With regard to the role of gender, our results correspond to the finding of Enoch et al (2003) who reported an association of novelty seeking with the COMT Val/Val genotype in female but not male participants. In turn, the Met/Met genotype was related to high harm avoidance scores as well as high scores in neuroticism in female participants (Enoch et al, 2003; Eley et al, 2003). This may also fit the present results since harm avoidance and neuroticism characterize personality traits, which conceptually reflect an opposite dimension of the novelty dimension.

Of note, several authors found that genetic variants of the COMT gene play a role in personality dimensions in female subjects but not in male subjects (Kim et al, 2006; Stein et al, 2005; Qian et al, 2003; Eley et al, 2003). Interestingly a sexually dimorphic effect of COMT Val158Met alleles was also found in ADHD patients, wherein the Val allele may contribute to ADHD risk in female subjects (Qian et al, 2003). This finding is in line with our data, where Val allele is connected with the impulsivity-related behavior sensation seeking, which is a main characteristic of ADHD behavioral pattern (Qian et al, 2003). Of note, gender-by-COMTgenotype effects have also been observed for the performance in cognitive test (O'Hara et al, 2006) and for nicotine dependence (Beuten et al, 2006). Apart from the behavioral level, some evidence indicates that the COMT genotype also affects cerebral structure (Kates et al, 2006) or function (Rybakowski et al, 2002) in a gender specific way.

A possible explanation for the sexually dimorphic COMT gene effect could rely on the well investigated modulatory role of COMT on tissue levels of catecholestrogens (Liehr and Roy, 1990; Liehr and Ricci, 1996) since COMT is the principal enzyme in the conjugation pathway for estrogens. Accordingly, it has been shown that serum estrogen levels in women are significantly associated with the COMT genotype with $\mathrm{Val} / \mathrm{Val}$ women displaying the lowest estrogen concentrations (Worda et al, 2003). The association of the COMT genotype with carcinogenic burden in female subjects has also been explained by its estrogen metabolizing properties (Lavigne et al, 2001). In this model, the $\mathrm{Val} / \mathrm{Val}$ genotype would be associated with low estrogen levels resulting in higher risk taking/male behavior, which has been indicated by the high sensation seeking scores in
$\mathrm{Val} / \mathrm{Val}$ women in the present study. This explanation would be plausible since high estrogen levels in women have been previously shown to be related to lower thrill and adventure seeking scores in healthy human female subjects (Balada et al, 1993). Therefore, high circulating estrogen levels (eg, in pregnancy) would protect women against impulsive or risk taking behavior, which has-to our knowledge - not been studied yet.

The association of COMT genotype and sensation seeking may furthermore be explained by the pivotal role of the COMT for prefrontal function. For instance, decreased prefrontal dopamine activity as supposed for the $\mathrm{Val} / \mathrm{Val}$ genotype was associated with reduced signal-to-noise ratio of the prefrontal cortex (Winterer et al, 2006a,b). As low prefrontal cortical control is suggested to promote impulsivity (Meyer-Lindenberg et al, 2006), the results of our investigation may be explained in terms of prefrontal function. This interpretation is in line with the observation that diminished frontal dopaminergic neurotransmission leads to an upregulation of midbrain dopamine activity (Deutch, 1993; Tsai et al, 2004). It is known from animal experiments that unfamiliar environments are accompanied by a robust increase of dopamine (Ihalainen $e t$ al, 1999) and a rapid respond of dopamine neurons with burst of spikes (Ljungberg et al, 1992). Lisman and Grace (2005) introduced a model integrating prefrontal functions with a subcortical circuitry involving the ventral tegmental area, the nucleus accumbens and hippocampus. Here, the prefrontal cortex was seen as a correlate of goal-related motivation and salience information acting on novelty signals from subcortical dopaminergic pathway.

Our finding indicates that high enzyme activity of COMT as represented by the $\mathrm{Val} / \mathrm{Val}$ genotype affects a basic personality dimension in humans and suggests an exclusive role in female subjects.

\section{ACKNOWLEDGEMENTS}

The project was supported by grants of the Deutsche Forschungsgemeinschaft (Sa434/3-1) and the German National Genome Research Network (01GS0479).

\section{REFERENCES}

Akil M, Kolachana BS, Rothmond DA, Hyde TM, Weinberger DR, Kleinman JE (2003). Catechol-O-methyltransferase genotype and dopamine regulation in the human brain. J Neurosci 23: 2008-2013.

Balada F, Torrubia R, Arque JM (1993). Gonadal hormone correlates of sensation seeking and anxiety in healthy human females. Neuropsychobiology 27: 91-96.

Benjamin J, Li L, Patterson C, Greenberg BD, Murphy DL, Hamer DH (1996). Population and familial association between the D4 dopamine receptor gene and measures of novelty seeking. Nat Genet 12: 81-84.

Beuten J, Payne TJ, Ma JZ, Li MD (2006). Significant association of catechol-O-methyltransferase (COMT) haplotypes with nicotine dependence in male and female smokers of two ethnic populations. Neuropsychopharmacology 31: 675-684.

Chakroun N, Doron J, Swendsen J (2004). Substance use, affective problems and personality traits: test of two association models. Encephale 30: 564-569. 
Chen J, Lipska BK, Halim N, Ma QD, Matsumoto M, Melhem S et al (2004). Functional analysis of genetic variation in catechol$O$-methyltransferase (COMT): effects on mRNA, protein, and enzyme activity in postmortem human brain. Am J Hum Genet 75: $807-821$.

Cloninger CR (1987). A systematic method for clinical description and classification of personality variants. A proposal. Arch Gen Psychiatry 44: 573-588.

Deutch AY (1993). Prefrontal cortical dopamine systems and the elaboration of functional corticostriatal circuits: implications for schizophrenia and Parkinson's disease. J Neural Transm Gen Sect 91: 197-221.

Ebstein RP, Novick O, Umansky R, Priel B, Osher Y, Blaine D et al (1996). Dopamine D4 receptor (D4DR) exon III polymorphism associated with the human personality trait of novelty seeking. Nat Genet 12: 78-80.

Eley TC, Tahir E, Angleitner A, Harriss K, McClay J, Plomin R et al (2003). Association analysis of MAOA and COMT with neuroticism assessed by peers. Am J Medl Genet 120B: 90-96.

Enoch MA, Xu K, Ferro E, Harris CR, Goldman D (2003). Genetic origins of anxiety in women: a role for a functional catecholO-methyltransferase polymorphism. Psychiatr Gen 13: 33-41.

Gallinat J (1996). Intensitätsabhängigkeit akustisch evozierter Dipolquellen und Persönlichkeit, Inaugural-Dissertation. Freie Universität: Berlin.

Gallinat J, Bajbouj M, Sander T, Schlattmann P, Xu K, Ferro EF et al (2003a). Association of the G1947A COMT (Val(108/ 158)Met) gene polymorphism with prefrontal P300 during information processing. Biol Psychiatry 54: 40-48.

Gallinat J, Kunz D, Lang UE, Kalus P, Juckel G, Eggers J et al (2005). Serotonergic effects of smoking are independent from the human serotonin transporter gene promoter polymorphism: evidence from auditory cortical stimulus processing. Pharmacopsychiatry 38: 158-160.

Gallinat J, Senkowski D, Wernicke C, Juckel G, Becker I, Sander T et al (2003b). Allelic variants of the functional promoter polymorphism of the human serotonin transporter gene is associated with auditory cortical stimulus processing. Neuropsychopharmacology 28: 530-532.

Heiman N, Stallings MC, Young SE, Hewitt JK (2004). Investigating the genetic and environmental structure of Cloninger's personality dimensions in adolescence. Twin Res 7: 462-470.

Ihalainen JA, Riekkinen Jr P, Feenstra MG (1999). Comparison of dopamine and noradrenaline release in mouse prefrontal cortex, striatum and hippocampus using microdialysis. Neurosci Lett 277: 71-74.

Kates WR, Antshel KM, Abdulsabur N, Colgan D, Funke B, Fremont W et al (2006). A gender-moderated effect of a functional COMT polymorphism on prefrontal brain morphology and function in velo-cardio-facial syndrome (22q11.2 deletion syndrome). Am J Med Genet B Neuropsychiatr Genet 141: 274-280.

Kim SJ, Kim YS, Kim SY, Lee HS, Kim CH (2006). An association study of catechol- $O$-methyltransferase and monoamine oxidase A polymorphisms and personality traits in Koreans. Neurosci Lett 401: 154-158.

Lachman HM, Papolos DF, Saito T, Yu YM, Szumlanski CL, Weinshilboum RM (1996). Human catechol-O-methyltransferase pharmacogenetics: description of a functional polymorphism and its potential application to neuropsychiatric disorders. Pharmacogenetics 6: 243-250.

Lang UE, Bajbouj M, Wernicke C, Rommelspacher H, DankerHopfe H, Gallinat J (2004). No association of a functional polymorphism in the serotonin transporter gene promoter and anxiety-related personality traits. Neuropsychobiology 49: 182-184.

Lavigne JA, Goodman JE, Fonong T, Odwin S, He P, Roberts DW et al (2001). The effects of catechol-O-methyltransferase inhibi- tion on estrogen metabolite and oxidative DNA damage levels in estradiol-treated MCF-7 cells. Cancer Res 61: 7488-7494.

Legault M, Wise RA (2001). Novelty-evoked elevations of nucleus accumbens dopamine: dependence on impulse flow from the ventral subiculum and glutamatergic neurotransmission in the ventral tegmental area. Eur J Neurosci 13: 819-828.

Liehr JG, Ricci MJ (1996). 4-Hydroxylation of estrogens as marker of human mammary tumors. Proc Nat Acad Sci 93: 3294-3296.

Liehr JG, Roy D (1990). Free radical generation by redox cycling of estrogens. Free Radical Biol Med 8: 415-423.

Lin CC, Su CH, Kuo PH, Hsiao CK, Soong WT, Chen WJ (2006). Genetic and environmental influences on schizotypy among adolescents in Taiwan: a multivariate twin/sibling. Analysis Behav Genet [E-pub ahead of print].

Lisman JE, Grace AA (2005). The hippocampal-VTA loop: controlling the entry of information into long-term memory. Neuron 46: 703-713.

Ljungberg T, Apicella P, Schultz W (1992). Responses of monkey dopamine neurons during learning of behavioral reactions. J Neurophysiol 67: 145-163.

McCourt WF, Gurrera RJ, Cutter HS (1993). Sensation seeking and novelty seeking. Are they the same? J Nerv Ment Dis 181: 309-312.

Meyer-Lindenberg A, Buckholtz JW, Kolachana BR, Hariri A, Pezawas L, Blasi G et al (2006). Neural mechanisms of genetic risk for impulsivity and violence in humans. Proc Natl Acad Sci USA 103: 6269-6274.

Noble EP, Ozkaragoz TZ, Ritchie TL, Zhang X, Belin TR, Sparkes RS (1998). D2 and D4 dopamine receptor polymorphisms and personality. Am J Med Genet 81: 257-267.

O'Hara R, Miller E, Liao CP, Way N, Lin X, Hallmayer J (2006). COMT genotype, gender and cognition in community-dwelling, older adults. Neurosci Lett 409: 205-209.

Qian Q, Wang Y, Zhou R, Li J, Wang B, Glatt S et al (2003). Familybased and case-control association studies of catechol$O$-methyltransferase in attention deficit hyperactivity disorder suggest genetic sexual dimorphism. Am J Med Genet B Neuropsychiatr Genet 118: 103-109.

Reuter M, Hennig J (2005). Association of the functional catechol$O$-methyltransferase VAL158MET polymorphism with the personality trait of extraversion. Neuroreport 16: 1135-1138.

Rybakowski JK, Borkowska A, Czerski PM, Hauser J (2002). Eye movement disturbances in schizophrenia and a polymorphism of catechol-O-methyltransferase gene. Psychiatry Res 113: 49-57.

Sheehan DV, Lecrubier Y, Sheehan KH, Amorim P, Janavs J, Weiller E et al (1998). The Mini-International Neuropsychiatric Interview (M.I.N.I.): the development and validation of a structured diagnostic psychiatric interview for DSM-IV and ICD-10. J Clin Psychiatry 59: 22-33.

Shiraishi H, Suzuki A, Fukasawa T, Aoshima T, Ujiie Y, Ishii G et al (2006). Monoamine oxidase A gene promoter polymorphism affects novelty seeking and reward dependence in healthy study participants. Psychiatr Genet 16: 55-58.

Stein MB, Fallin MD, Schork NJ, Gelernter J (2005). COMT polymorphisms and anxiety-related personality traits. Neuropsychopharmacology 30: 2092-2102.

Sullivan PF, Fifield WJ, Kennedy MA, Mulder RT, Sellman JD, Joyce PR (1997). Novelty seeking and a dopamine transporter gene polymorphism (DAT1). Biol Psychiatry 42: 1070-1072.

Tsai SJ, Hong CJ, Yu YW, Chen TJ (2004). Association study of catechol-O-methyltransferase gene and dopamine D4 receptor gene polymorphisms and personality traits in healthy young chinese females. Neuropsychobiology 50: 153-156.

Winterer G, Egan MF, Kolachana BS, Goldberg TE, Coppola R, Weinberger DR (2006a). Prefrontal electrophysiologic 'noise' and catechol-O-methyltransferase genotype in schizophrenia. Biol Psychiatry 60: 578-584. 
Winterer G, Musso F, Vucurevic G, Stoeter P, Konrad A, Seker B et al (2006b). COMT genotype predicts BOLD signal and noise characteristics in prefrontal circuits. Neuroimage 32: 1722-1732. Worda C, Sator MO, Schneeberger C, Jantschev T, Ferlitsch K, Huber JC (2003). Influence of the catechol-O-methyltransferase (COMT) codon 158 polymorphism on estrogen levels in women. Hum Reprod 18: 262-266.
Zuckerman M (1979). Sensation Seeking: Beyond The Optimal Level of Arousal. Lawrence Erlbaum Associates: Hillsdale, New Jersey.

Zuckerman M (1990). The psychophysiology of sensation seeking. J Pers 58: 313-345.

Zuckerman M, Kuhlman DM (2000). Personality and risk-taking: common biosocial factors. J Pers 68: 999-1029. 